УДК 78.03

\title{
T. Казначеева
}

\section{НАЦИОНАЛЬНЫЕ ТАНЦЕВАЛЬНЫЕ ТЕНДЕНЦИИ В ОПЕРАХ «ОСАДА ДУБНО» П. СОКАЛЬСКОГО И «ТАРАС БУЛЬБА» Н. ЛЫСЕНКО НА СЮЖЕТ Н. ГОГОЛЯ}

Статья посвящена рассмотрению вопросов проявления национальных танцевальных тенденций в оперном творчестве украинских композиторов кониа XIX - начала XX веков. Воплощение специфических особенностей танцевальных жанров европейской и украинской танцевальной культуры рассматривается на примере опер «Осада Дубно» П. Сокальского и «Тарас Бульба» Н. Лысенко, основанных на сюжете повести Н. Гоголя.

Ключевые слова: опера, танцевальный жанр, большая танцевальная форма, малая танцевальная форма, полонез, гопак, казачок.

В современный период бурного возрождения национальной украинской культуры особое значение приобретают вопросы становления национального музыкального и оперно-театрального искусства в Украине.

Специфика драматургии оперы отличается расширением выразительных возможностей с помощью как слуховой сферы восприятия музыкальных образов, так и зрелищных средств воплощения художественного замысла в сценических формах музыкального искусства. Опера представляет собой драматургическое целое, в котором музыкальная, театральная и танцевальная составляющие находятся в тесном взаимодействии. Выявление и изучение принципов существования танцевальных жанров в контексте оперного искусства составляет предмет многих современных музыковедческих исследований. Однако вопрос о специфических особенностях воплощения танцевальных жанров в операх украинских композиторов XIX века еще не исследован в достаточной степени. В связи с этим особое значение приобретает рассмотрение проблемы реализации в жанре оперы украинского народного бытового танца, который, прежде всего, связан с сохранением национальных традиций. Указанные позиции составляют актуальность и цель данной статьи.

Процесс развития жанра оперы в XIX веке характеризуется появлением значительного количества самобытных произведений украинских композиторов. Практически в каждом из них проявляются специфические особенности танцевальных жанров европейской и

(C) Казначеева Т., 2015 
украинской танцевальной культуры. Танцевальные жанры - исторически сложившиеся роды и виды музыкально-пластических произведений, близкие по содержанию многим типическим средствам музыкальной и пластической выразительности, имеющие общую социальную и этническую среду происхождения и жизненного назначения.

Проанализируем основные танцевальные эпизоды опер «Осада Дубно» П. Сокальского и «Тарас Бульба» Н. Лысенко, особенности их воплощения и влияние на типологические свойства драматургии.

Опера «Осада Дубно» занимает особенно место в истории украинской оперы. П. Сокальский первым из украинских композиторов обратился к сюжету повести Н. Гоголя «Тарас Бульба». Либретто оперы, написанное самим композитором, содержит существенные изменения и дополнения (по сравнению с литературным первоисточником). Масштабное оперное произведение состоит из пролога и четырех действий. Начата опера в 1876 году, издана - в 1884. В монографии 3. Юферовой указано, что в Харькове, в доме брата композитора Ивана Петровича Сокальского - на одном из аматорских музыкальных вечеров силами местных и гастролирующих в городе музыкантов и артистов была исполнена опера «Осада Дубно» [5, с. 18].

В оркестровом вступлении (№ 1) пролога оперы (до поднятия занавеса) композитором уже полностью подготовлено ритмическое насыщение и тональная сфера последующего танцевального эпизода.

Весь танцевальный фрагмент Allegro moderato alla Polacca проходит на заднем плане: из комнаты панны Урсулы, дочери киевского воеводы, виден зал с колоннадой, где гости проходят полонезом [4, с. 3-5].

Полонез (франц. Polonaise - польский) был известен первоначально как общественный танец-шествие. Польский крестьянский танец, предшествовавший появлению полонеза, был четырехдольным, исполнялся на сельских праздниках, которые открывались медленным, «пешим» (chodzony) танцем [1, с. 368]. В XVIII-XIX веках (особенно после Великой французской революции) стал широко распространен по всей Европе как парный бальный танец, открывающий торжества. Благодаря массовому характеру и достаточно простым движениям полонез задавал тон всему балу.

Полонез в опере П. Сокальского наполнен торжествующим До мажором, создающим образ победителей. Несмотря на внутренние повторы, вариантность построения танцевальный эпизод в целом характеризуется сквозным развитием: АВСД. Каждый раздел, что ха- 
рактерно для данного танцевального жанра, завершается совершенными кадансами. Отметим, что различные ритмоформулы полонеза сохраняются на протяжении всего пролога (№ 2, 4, 5):

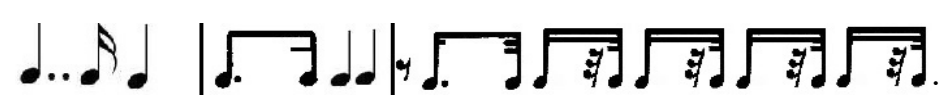

Внутренняя структура полонеза достаточно нетрадиционна, композитор предлагает оригинальную, самобытную трактовку данного жанра.

Строение первой части (А) выглядит достаточно оригинально, характеризуется сквозным развитием. П. Сокальский разрушает классическую танцевальную квадратность, намечая будущую противоречивость драматургии:

$\begin{array}{cccc}\text { A } & \text { R } & \text { A1 } \\ \text { C } & \text { a-d a e } & \text { C } \\ 3+3 & 3+2+2+\underset{\rightarrow}{2} & 3 \text { o.п. }+2 \\ 6 \mathrm{~T} & 7 \mathrm{~T} & 5 \mathrm{~T}\end{array}$

Средняя часть полонеза (В) написана в достаточно далекой тональности - Ля-бемоль мажор (As-dur). Этой части свойственны: более мелодизированный тематический материал, другой тип динамики (crescendo, sf). По-прежнему нарушается квадратная структура, вновь следует трехтакт в более медленном темпе и rallentando - успокоение. Меняется ритмоформула, автор использует классический вариант полонеза:॰... . .

Затем возвращается трехтактная структура $(\mathrm{C})$, появляется еще один ритмический рисунок:

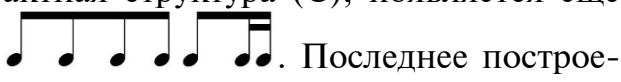
ние расширено за счет секвенций, применения вариантных ритмоформул и активного утверждения тональности доминанты (G-dur). В двух последних тактах (перед доминантовым органным пунктом) целый ряд отклонений в мелодических фигурациях и альтерированный аккорд двойной доминанты (IV6 \#1b3).

В завершении пролога находится тональная, но не тематическая, реприза (Д), которая характеризуется тональным возвращением в 
C-dur, при постоянном обновлении ритмоинтонационной ситуации, различном тембровом содержании. Впервые полонез предвосхищен доминантовыми, «приглашающими» сигналами. Тональная реприза по своей структуре более цельная, отличается от основного полонеза отсутствием разделительных и совершенных кадансов: 3 такта $(\mathrm{C}-\mathrm{d}), 4$ такта $\left(Д_{3}^{4} \rightarrow \mathrm{C}\right)$ и затем 6 тактов ярчайшего утверждения основной тональности (C-dur). Особенности гармонии: ряд отклонений, использование альтерированных аккордов двойной доминанты (перед $\mathrm{K}_{4}^{6}-Д_{5}^{6} \# 1$, переходящий в ДД $4_{3}^{4} \# 1$ ).

Кода интересна тембральным решением, «кричащими», фанфарными форшлагами. Отличается оригинальным построением по принципу дробления: $4+4+2+2+2$ (органный пункт) +4 (тонический органный пункт).

В опере П. Сокальского полонез начинает формирование «польского образа» (как у М. Глинки в опере «Иван Сусанин»), ярко и достаточно разнообразно воплощенного в произведении. Отметим, что в ходе дальнейшего развития музыкальной драматургии оперы полонез приобретает значение лейтжанра. Характерные танцевальные ритмы (ритмоформулы полонеза, мазурки) многократно появляются в партии оркестра на протяжении всей оперы (особенно в прологе и двух картинах третьего действия) и приобретают значение лейтритмов и лейтмотивов. Танцевальные элементы появляются даже на фоне музыкальной характеристики героико-эпического образа Тараса Бульбы, как предвосхищение конфликтного противостояния.

Помимо использования специфических особенностей жанров полонеза и мазурки, ярко воплощающих национальные танцевальные тенденции, для создания «польского образа» композитор использует также жанр вальса.

Темп и ритм вальса в ариозо (№ 4) панны Урсулы удивительно точно передают ее внутреннее состояние. Разнообразные ритмические секвенции создают легкий, танцевальный образ.

Однако центральным образом драмы, воплощенным в опере П. Сокальского, становится образ украинского народа. Его музыкальная характеристика опирается на песенный и танцевальный украинский и русский фольклор. Композитор использует танцевальные жанры гопака, казачка, а также создает сцены, в которых танец синтезируется с хором. Мелодии гопака и казачка появляются в первом (№ 11 пляска с хором) и во втором действии оперы (№ 20 пляска с песней в сцене пирушки запорожцев). 
В № 11 - пляска с хором (Allegro assai, B-dur) - различные варианты цитатно используемых типичных народных песенных интонаций в сочетании с партией оркестра и характерных танцевальных составляющих создают яркую жанровую картину украинского быта [4, c. 90-103].

После двух тактов вступления звучит хор, в партии которого соединились женское начало (сопрано) и более спокойная линия мужских голосов (тенора и басы). Экспрессивная оркестровая партия дублирует и синтезирует двуплановые хоровые линии. Мелодический материал основан на украинской народной песне «Ой варила горлиця лободу» и, соответственно, имеет куплетную форму строения.

Самостоятельные куплеты с постоянными оркестровыми проигрышами, контрастной второй частью и репризностью («Ой варила горлиця») в одной и той же тональности (B-dur).

Отметим полисодержательность данного номера: нередко оркестровая партия стремится к legato, а имитационная сфера представляет собой типично игровой элемент («дыб, дыб, на село»).

Приведем схему пляски:
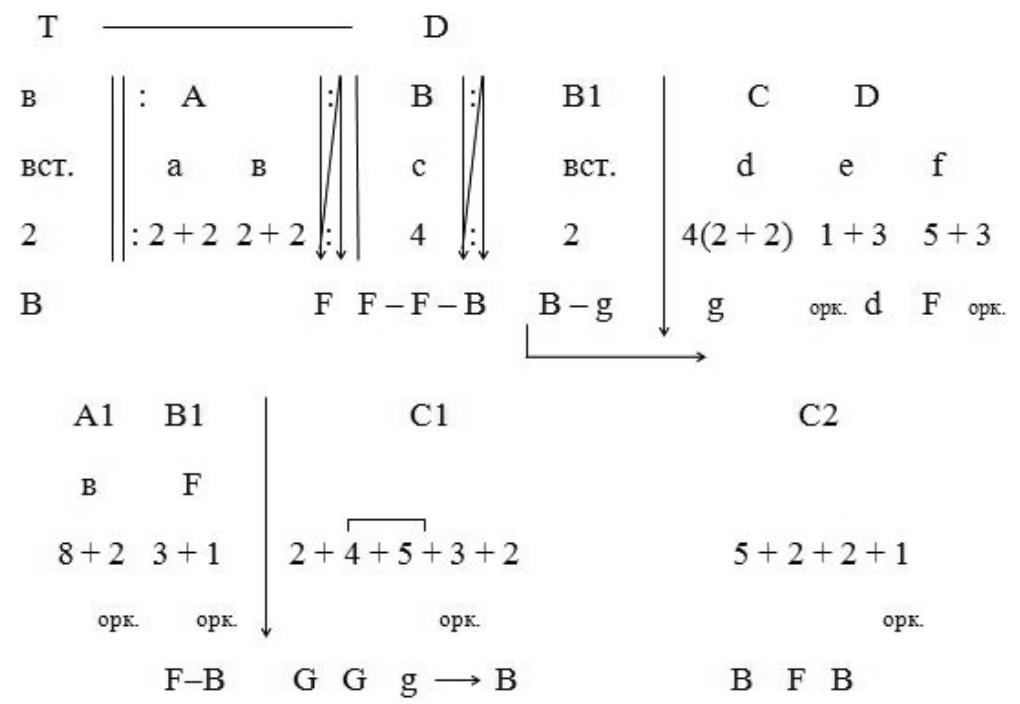

В № 20 - пляске с песней [4, с. 194-201] композитор точно воссоздает эмоциональную экспрессивность, энергичность и воинственный огненный темперамент украинского этноса. От медленных, простых 
шагов исполнители танца постепенно переходят к быстрым, виртуозным движениям. Манеру их исполнения очень точно описывает Н. Гоголь: «Около молодого запорожца четверо старых выработывали довольно мелко ногами, вскидывались, как вихорь, на сторону, почти на голову музыкантам, и, вдруг опустившись, неслись вприсядку и били круто крепко своими серебряными подковами плотно убитую землю. Земля глухо гудела на всю округу, и в воздухе далече отдавались гопаки и тропаки, выбиваемые звонкими подковами сапогов» [2, c. 228-229].

В целом танцевальные номера оперы «Осада Дубно» П. Сокальского образуют большую танцевальную форму - совокупность отдельных танцевальных эпизодов, рассредоточенных по всей опере, более или менее оформленных, но скрепленных единым принципом драматургического развития. Танцевальные жанры, входящие в состав большой танцевальной формы данной оперы, играют важную роль в драматургии произведения: жанрам полонеза, мазурки и вальса, которые являются олицетворением польского лагеря, композитор противопоставляет танцевальные жанры, которые провозглашают украинскую ментальность (гопак, казачок). Отметим, что данный образец большой танцевальной формы имеет полижанровую основу. Помимо постоянно внедряемого лейтжанра полонеза, пронизывающего всю оперу, начиная со вступления, важную роль играют также жанры мазурки, вальса и бытовой украинской пляски.

Сюжет повести Н. Гоголя «Тарас Бульба» находит значительное по художественной силе воплощение и в одноименной опере Н. Лысенко - выдающемся образце украинского музыкально-театрального искусства. Монументальная историко-героическая опера «Тарас Бульба» - вершина профессионального мастерства композитора. В первоначальном виде клавир оперы был издан в 1913 году. Первая постановка: Харьков, 4 октября 1924 года. В процессе длительной работы на основе различных вариантов была создана музыкальная редакция Л. Ревуцкого и литературная редакция М. Рыльского (1964).

Аналогично тенденции, созданной М. Глинкой (в опере «Иван Сусанин») и продолженной П. Сокальским (в опере «Осада Дубно»), Н. Лысенко использует прием противопоставления двух контрастных музыкальных образов: украинского и польского. Причем композитор противопоставляет как индивидуальные образы, так и коллективные. Кроме того, отметим, что противопоставление двух контрастных танцевальных образов создает завязку драматургического конфликта. 
В первой сцене, на площади перед Братским монастырем, после эпичной думы кобзаря (фигура народного певца, введенная в оперу, отсутствует в повести Н. Гоголя) следует эпизод (Andantino), в котором меняется музыкальный размер (3/4) и звучит характерная ритмоформула полонеза - пунктирный ритм, в сочетании с короткими форшлагами. Подобные музыкальные средства, типичные для польской танцевальной музыки, создают яркий, характерный национальный образ. В ходе дальнейшего развития музыкальной драматургии пунктирный ритм становится лейтритмом, характеризующим польскую шляхту.

Контрастно ему звучит танцевальная мелодия кобзаря «А мій батько орандар, чоботар», в которой ясно ощутим ритм, свойственный казачку, синкопы, музыкальный размер - 2/4. Н. Лысенко создает оригинальную мелодию: использует вариационный принцип изложения, характерный для украинских народных танцевальных мотивов, и, таким образом, выражает особенности, присущие национальной ментальности. В данном случае это и проявление эмоциональности, ироничности. К мелодии кобзаря присоединяется четырехголосный хор и в кульминации сцены (poco piu mosso) удалая мелодия оркестра завершает яркую жанровую картину народной пляски. Музыкальное противопоставление двух контрастных танцевальных образов (украинского и польского) создает завязку драматургического конфликта. Народ встает на защиту кобзаря, не дает его обидеть, возникает стычка, и Остап с бурсаками отступает к воротам монастыря.

Во второй картине, с появлением дочери польского воеводы, в мелодии сопровождения снова возникает пунктирный лейтритм. Далее Марыльця поет беззаботную ариетту в форме мазурки «Я родилась у палатах». Эпизод встречи с Андрием основан на вальсовом движении. С появлением воеводы (Maestoso) вновь в партии оркестра появляется пунктирный лейтритм. Во втором действии на хуторе Тараса Бульбы сходятся гости, начинаются песни и пляска: «Ой дівчина горлиця» с хором.

В развитии драматургии второго действия оперы важную роль играет танец казачок (Allegro, D-dur). Он представляет собой характерный пример малой танцевальной формы - танец, внедренный в драматургию оперного действия, отличающийся четкостью и завершенностью структуры, который в композиции оперы образует яркую, но кратковременную жанрово-видовую вставку. Казачок воплощает такие специфические особенности танцевальной менталь- 
ности украинского этноса как шутливость, живость, подвижность и динамичность.

В композиции казачка Н. Лысенко использует нетрадиционный, нестандартно изложенный вариант рондальной формы, в которой рефрен приобретает значительное развитие, постоянно вариантно повторяясь. Отметим также черты свободы изложения, противоречивые сопоставления, моноинтонационность и постоянную интонационную вариационность на протяжении всего танцевального номера [3, c. 130-137].

Проанализируем структуру танца:

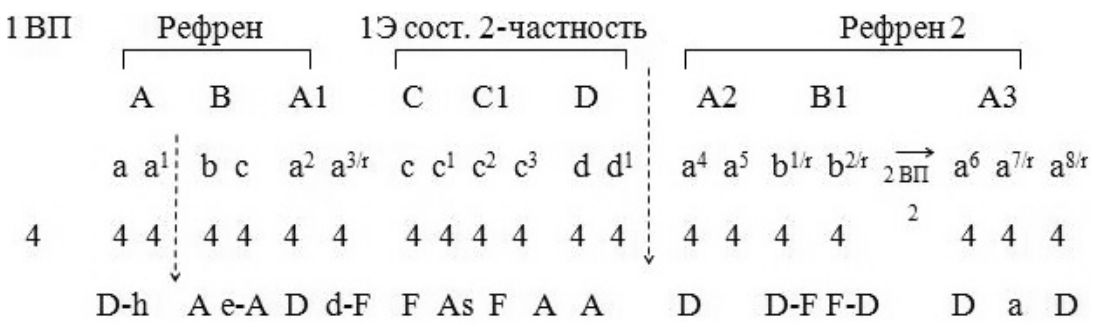

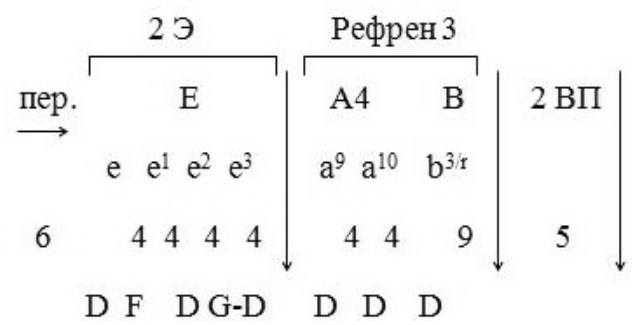

Материал первой вступительной партии характеризуется длительным использованием доминанты, переходящей в тонику уже в самом танце. Специфический рефрен: простая трехчастная форма, ее реприза разомкнута - последнее предложение представляет собой переход к первому эпизоду, наиболее сложному и развитому. Это составная двухчастная форма; характеризуется терцовым сопоставлением тональностей предложений: основные - F-dur, производные As-dur, A-dur. Контрастный раздел (D) утверждает A-dur, переходя во второй рефрен, который является вариацией первого (наиболее близок первый период - a4, a5). 
Середина, несмотря на сохранение квадратной структуры $(4+4)$, является разработкой второго элемента (b), который в дальнейшем звучать не будет. Затем композитор достаточно неожиданно вводит два такта второй вступительной партии перед репризой рефрена. Расширенная реприза состоит из трех предложений. Переход - развитие ко второму эпизоду (Е), который тонально наиболее близок к рефрену, хотя в нечетных предложениях - уход в другие тональности (F-dur, G-dur).

Структура второго эпизода напоминает начальный раздел первого эпизода: здесь также четыре предложения по четыре такта (e, e1, e2, е3), также присутствует первоначальное терцовое сопоставление тональностей.

Третий рефрен - сокращенный, разомкнутый. Первоначальный материал наиболее близок к экспозиционному. Вторая часть (В) расширена до девяти тактов. Весь рефрен звучит в основной тональности.

Завершается танец музыкальным материалом второй вступительной партии (5 тактов, литавры, sf, ff).

Отметим основные принципы изложения музыкального материала казачка в опере Н. Лысенко:

- повтор на уровне тактов, предложений и периодов;

- секвенции (однотональные и модулирующие);

- вариантность и вариационность; однако даже контрастные элементы во многом производны: мотивы в инверсии, в противодвижении, ритмические варианты трансформации;

- опевания различного типа;

- секундовое и терцовое движение;

- гаммообразные движения: восходящие тетрахорды в миноре, диатоническое и хроматическое движение в мелодической линии и в сопровождении;

- кадансовые обороты связаны как с завершающим элементом предыдущего, так и с началом последующего материала, создают выход за пределы квадратности.

Разнообразные танцевальные эпизоды оперы «Тарас Бульба» Н. Лысенко образуют большую танцевальную форму. Данное построение состоит из нескольких эпизодов, в которых украинские танцевальные жанры представлены массовыми плясками, колоритными жанровыми сценами и одной из самых популярных жанровых разновидностей (танцем казачок). Польский образ формируется благодаря использованию в оркестровой партии типично танцевальных 
средств: пунктирного лейтритма полонеза, а не полноценного танца (четвертое действие, появление воеводы - Moderato pomposo), жанра мазурки и вальсового движения (в создании лирического образа дочери воеводы).

Таким образом, рассмотренные танцевальные эпизоды оперы «Осада Дубно» П. Сокальского позволяют констатировать использование композитором разнообразных танцевальных жанров, в которых выразительно проявляются национальные танцевальные тенденции. Польский лагерь характеризуется с помощью таких типичных жанров европейской танцевальной культуры, как полонез, мазурка и вальс. Этим жанрам композитор противопоставляет жанры бытовой украинской пляски (гопак, казачок), провозглашающие украинскую ментальность.

Продолжая тенденции трактовки танцевальных жанров П. Сокальского, Н. Лысенко поднял их до более профессионального уровня. В опере «Тарас Бульба» Н. Лысенко нет монументальных, замкнутых танцевальных номеров, характеризующих польский лагерь. Композитор решает проблему нахождения национальной идентичности, используя лейтритмы полонеза, жанр мазурки и вальсовое движение. Относительно проявления характерных особенностей украинской ментальности отметим, что оно наиболее показательно сказывается в выборе обобщающей интонационной сферы произведения, которая воплощает типичные черты бытовых танцевальных жанров, в присутствии песенных оборотов и в применении вариационного подхода.

\section{СПИСОК ЛИТЕРАТУРЫ}

1. Бэлза И. Ф. Полонез / И. Ф. Бэлза // Музыкальная энциклопедия / [гл. ред. Ю. В. Келдыш]. - М. : Советская энциклопедия, 1973. - Т. 4. - 1978. C. $368-369$.

2. Гоголь Н. В. Избранные сочинения : в 2 т. / Н. В. Гоголь ; [вступ. статья П. Николаева; примеч. Н. Степанова, А. Бушмина, Г. Фридлендера]. - М. : Художественная литература, 1984. - Т. 1. -575 с.

3. Лисенко М. В. Тарас Бульба. Історична опера на п'ять дій, сім картин : клавір / М. В. Лисенко. - К. : Мистецтво, 1964. - 348 с.

4. Сокальский П. П. Осада Дубно. Опера в четырех действиях / П. П. Сокальский. - С. Петербург : Нотопечатня В. Бесселя и $\mathrm{K}^{\circ}, 1884 .-440$ c.

5. Юферова 3. Б. Дон-диез «Южного края»: золотые россыпи композиторского и музыкально-критического наследия Владимира Сокальского : [монография] / З. Б. Юферова. - Харьков : С. А. М., 2014. - 404 с. 
Казначесва Т. Національні танщювальні тенденції в операх «Облога Дубно» П. Сокальського $i$ «Тарас Бульба» М. Лисенка на сюжет М. Гоголя.

Стаття присвячена розгляду питань втілення національних танцювальних тенденцій в оперній творчості українських композиторів кінця XIX - початку XX століть. Втілення специфічних особливостей танцювальних жанрів європейської та української танцювальної культури розглядається на прикладі опер П. Сокальського «Облога Дубно» і М. Лисенка «Тарас Бульба», заснованих на сюжеті повісті М. Гоголя.

Ключові слова: опера, танцювальний жанр, велика танцювальна форма, мала танцювальна форма, полонез, гопак, козачок.

Kaznacheeva T. National dance trends in operas «The siege of Dubno» by P. Sokalskiy and «Taras Bulba» by N. Lysenko based on the story by N. Gogol.

The article is devoted to the existence of national dance trends in opera works of Ukrainian composers of the late XIX - early XX centuries. The embodiment features of the dance genres of Ukrainian and European dance culture are considered on the example of operas by P. Sokalskiy «The Siege of Dubno» and N. Lysenko «Taras Bulba» based on the story novel by N. Gogol.

Keywords: opera, dance genre, great dance form, small dance form, Polonaise, Gopak, Kazachok.

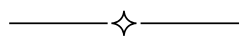

\section{Н. Лысенко}

\section{ПОЭТИКА ЖАНРА КАНТАТЫ И ЕЕ ПРЕТВОРЕНИЕ В ХОРОВОМ ТВОРЧЕСТВЕ С. С. ПРОКОФЬЕВА}

Статья посвящена рассмотрению исторических и эволюционных путей становления жанра кантаты в западноевропейской и русской музыкально-исторической традиции, а также особенностям претворения ее поэтики в хоровом творчестве С. С. Прокофьева. Жанр кантаты, сопутствующий практически всем периодам деятельности композитора («Семеро их», «Александр Невский» и др.), отразил не только стилевую специфику его твориества, но и культурно-исторические и духовные искания его эпохи.

Ключевые слова: кантата, кантата «на случай», хоровое творчество С. С. Прокофьева, мифопоэтика культуры соиреализма.

В 1927 г. А. Ф. Лосев в своем исследовании, посвященном изучению диалектики мифа, отмечал, что данный феномен составляет «... трансцендентально-необходимую категорию мысли и жизни.

(C) Лысенко Н., 2015 